\title{
Prevention of neurological damage during open-heart surgery
}

\author{
M. A. B R A N T H W A I T E
}

Brompton Hospital, London SW3

\begin{abstract}
Branthwaite, M. A. (1975). Thorax, 30, 258-261. Prevention of neurological damage during open-heart surgery. A previous study of neurological damage related to openheart surgery suggested that the onset of cardiopulmonary bypass is a time of particular hazard, and there is evidence that both microemboli from the extracorporeal circulation and inadequate cerebral perfusion may be contributory factors.

Measures to eliminate or minimize these hazards have been introduced, and a clinical survey has been undertaken to evaluate their efficacy. There has been a very highly significant decrease in the incidence of neurological damage as judged by comparison with the results of a similar survey carried out before these measures were introduced.

In spite of limitations imposed by differences in workload, perfusion techniques, and methods of data collection, it is concluded that the prophylactic measures have been responsible for the reduction in the incidence of neurological damage.
\end{abstract}

A previous clinical survey, based upon the retrospective analysis of the case notes of 417 patients submitted to open-heart surgery during 1970 , revealed an incidence of neurological damage of $19.2 \%$ (Branthwaite, 1972). Evidence derived by monitoring cerebral function with a heavily filtered electroencephalograph (Cerebral Function Monitor, Devices Ltd) suggested that the onset of perfusion is a time of particular hazard (Branthwaite, 1973). Microemboli from the extracorporeal apparatus, and inadequate cerebral perfusion caused by an abrupt change in the character and magnitude of the perfusing pressure, could contribute to these findings, and there is experimental and clinical evidence which suggests that both factors may be of importance (Stone et al., 1967; Hasbrouck and Rigor, 1969; Javid et al., 1969; Patterson and Kessler, 1969; Hill et al., 1970; Osborn et al., 1970; Tufo, Ostfeld, and Shekelle, 1970; Egeblad et al., 1972; Sanderson, Wright, and Sims, 1972; Branthwaite, 1974). Since 1970, filters for microemboli have been incorporated into the extracorporeal circuit used in this hospital both on the arterial line (Barrier filter-Johnson and Johnson), and on the coronary suction lines (Bromlus filter-Lusterlite Products Ltd.), and the hazards of sudden hypotension, particularly at the onset of bypass, have been recognized. Vasop'essor agents are given if hypotension occurs

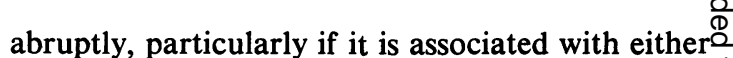
depression on the cerebral function monitor $\overrightarrow{\overrightarrow{0}}$ (Figure) or dilatation of the pupils. A second sur 3 vey was undertaken during 1973 to evaluate the efficacy of these measures.

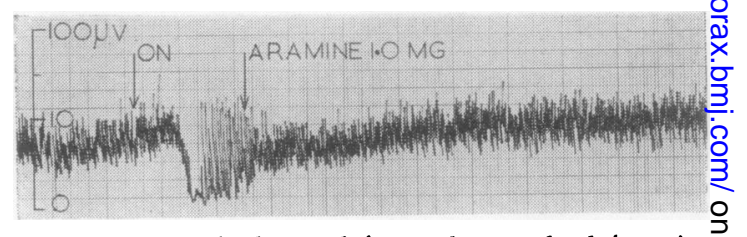

FIGURE Record obtained from the cerebral function monitor at the onset of perfusion in a 43-year-old woman with mild mitral stenosis and hypertension $(160 / 100 \mathrm{mmHg})$. The arterial blood pressure fell tos between 30 and $40 \mathrm{mmHg}$ when the aorta was cross 0 clamped, in spite of a flow of $80 \mathrm{ml} / \mathrm{kg}$ per minutê from the oxygenator. The resulting cerebral depres $\omega$ sion was reversed rapidly by the administration of metaraminol (Aramine), and the patient regaines consciousness after the operation without an) evidence of neurological deficit. Paper speed? $6 \mathrm{~mm} / \mathrm{min}$.

\section{MATERIAL AND METHODS}

The case notes of all patients submitted to open $\frac{\mathbb{D}}{2}$ heart surgery during 1973 were inspected. The्g data were collected retrospectively to preserven 
comparability with the methods used in 1970 , and the same criteria were used to define neurological damage. These criteria were impairment of consciousness, voluntary movement or vision, separately or together, apparent within three days of operation. Impaired consciousness ranged from coma to confusion of a severity sufficient to interfere with response to simple commands, but confusion alone in patients who were hypoxic postoperatively (arterial oxygen tension less than $60 \mathrm{mmHg}$ ) was discounted.

The factors considered in relation to neurological damage in 1973 are listed (Table I). Information on one or more of these factors was unavailable in 23 patients, and these were excluded from the statistical analysis. The collection of data was complete for all patients who suffered neurological damage.

T A B L E I

FACTORS CONSIDERED IN RELATION TO INCIDENCE OF NEUROLOGICAL DAMAGE

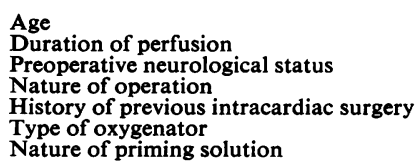

The association between the factors listed in Table I and the incidence of neurological damage was analysed by multiple regression analysis so that the influence of interrelationship between some of the variables could be eliminated.

\section{RESULTS}

Neurological damage was sustained by 40 of the 538 patients who survived the operative procedure (Table II). The incidence of 7.4\% compares with a corresponding figure of $19.2 \%$ in 1970 , and this difference is very highly significant $(P<0.001)$. Nineteen of the 40 patients died in the postoperative period, and the neurological lesion was

\section{T A B L E I I}

NATURE OF NEUROLOGICAL DAMAGE SUSTAINED IN

\begin{tabular}{l|rr}
\hline Hemi-or mono-plegia or paresis & 14 & $(36)$ \\
Coma & 16 & $(20)$ \\
Confusion & 10 & $(22)$ \\
Quadriplegia & 1 & $(1)$ \\
Epilepsy & 1 & $(2)$ \\
Midbrain lesion & - & $(2)$ \\
\hline
\end{tabular}

Figures in parentheses are the comparable values for 1970

Three patients in 1970 and two in 1973 had localizing signs of a hemiplegia, as well as coma. wholly or partly responsible in 10 cases. Twelve of the 21 patients with neurological damage who survived to leave hospital were left with residual disability of varying severity at the time of their discharge.

Probable aetiological events were suspected on clinical grounds in 22 of the patients who sustained neurological damage in 1973 (Table III) and nine of these patients were aged 5 or less. The incidence of neurological damage which could not be attributed to any specific feature of the operative period fell from $11.5 \%$ (48 of 417 cases) in 1970 to $3.4 \%$ (18 of 538 cases) in 1973 $(\mathbf{P}<0.001)$.

\section{T A B L E I I I}

SUSPECTED AETIOLOGY OF NEUROLOGICAL DAMAGE IN 22 PATIENTS

\begin{tabular}{|c|c|c|c|c|}
\hline \multicolumn{4}{|c|}{$\begin{array}{l}\text { Hypotension, hypoxia or cardiac arrest } \\
\text { Suspected embolism of clot or air } \\
\text { 'Hypernatraemia } \\
\text { 'Vertebral steal' syndrome }{ }^{2} \\
\text { Uraemia } \\
\text { Cerebral abscess }\end{array}$} & \multirow{2}{*}{$\begin{array}{r}15 \\
2 \\
2 \\
1 \\
1 \\
1 \\
\end{array}$} \\
\hline & $\begin{array}{l}22 \text { Cases } \\
\text { Aetiology } \\
\text { suspected }\end{array}$ & $\begin{array}{l}18 \text { Cases } \\
\text { Aetiology } \\
\text { unknown }\end{array}$ & $\begin{array}{l}\text { Mean Diff. } \\
\pm \text { SE of } \\
\text { Mean }\end{array}$ & \\
\hline $\begin{array}{c}\text { Age (yr) } \\
\text { Duration } \\
\text { of bypass } \\
\text { (min) }\end{array}$ & $\begin{array}{r}30 \cdot 0 \\
134 \cdot 3\end{array}$ & $\begin{array}{r}53 \cdot 1 \\
116 \cdot 6\end{array}$ & $\begin{array}{l}23 \cdot 1 \pm 7 \cdot 0 \\
17 \cdot 7 \pm 25 \cdot 1\end{array}$ & $\begin{array}{l}<0.01 \\
>0.1\end{array}$ \\
\hline
\end{tabular}

${ }^{1}$ Complicating inadequate removal of salt crystals from the membrane oxygenator.

'During resection of a thoracic aortic aneurysm.

Those factors which were found to be positively associated with an increased incidence of neurological damage in 1970 continued to feature in 1973 (Table IV). These were age, increasing duration of perfusion, and the presence of a previous neurological lesion. Use of an all-blood prime appeared as an additional contributory factor in 1973, but neither the nature of the operation nor a history of previous cardiac surgery were important. There was a quadratic relationship between age and neurological damage

T A B L E I V

FACTORS ASSOCIATED WITH NEUROLOGICAL DAMAGE: RESULTS OF MULTIPLE REGRESSION ANALYSIS

\begin{tabular}{l|cc}
\hline & $\begin{array}{c}\text { Variance } \\
\text { Ratio }\end{array}$ & Significance \\
\hline Duration of perfusion & $27 \cdot 3$ & $<0.01$ \\
Preoperative neurological abnormality & $10 \cdot 0$ & $<0.01$ \\
Use of an all-blood prime & $9 \cdot 4$ & $<0.01$ \\
Age $^{1}$ & $4 \cdot 7$ & $<0.05$
\end{tabular}

${ }^{1}$ There was a quadratic relationship between age and neurological damage. 
in 1973, probably accounted for by the higher incidence of specific complications in the very young.

\section{DISCUSSION}

Analysis of the results obtained in $1970 \mathrm{em}$ phasized the importance of perfusion in the aetiology of neurological damage. Since that time prophylactic measures have been introduced and there has been a very highly significant decrease in the incidence of neurological damage. Before it can be concluded that these events are causally related, it is necessary to explore the validity of the comparison between the results in 1970 and in 1973.

There have been a number of changes in the nature of the work and the techniques of perfusion between 1970 and 1973 (Table V). The type of operative procedure was unrelated to the occurrence of neurological damage in their series, and the choice of oxygenator was also unimportant, apart from an apparently favourable influence of perfusion with the Temptrol in 1970. The virtual exclusion of this oxygenator during 1973 would be expected to enhance, rather than diminish, the incidence of neurological damage, and it is regarded therefore as an unimportant difference between the two years.

Use of an all-blood prime was an unfavourable feature in 1973, although the nature of the priming solution did not influence the neurological outcome in 1970. More patients in 1970 were subjected to perfusion from apparatus which had been primed with whole blood, but the number involved (59) was relatively small. It is highly un-

\section{T A B L E V}

COMPARISON OF THE WORK AND PERFUSION TECHNIQUES IN 1970 AND 1973

\begin{tabular}{l|rr} 
& 1970 & 1973 \\
\hline Operative procedure & 142 & 140 \\
Mitral valve surgery & 115 & 111 \\
Aorta and aortic valve surgery & 31 & 94 \\
Multiple valve replacement & 56 & 84 \\
Left to right shunts & 39 & 37 \\
Right to left shunts & 16 & 9 \\
Relief of right heart obstruction & 10 & 44 \\
Ischaemic heart disease & 8 & 19 \\
Miscellaneous & 326 & 428 \\
\hline Oxygenator & 56 & 82 \\
Rotating disc & 30 & 4 \\
Rygg & 0 & 20 \\
Temptrol & & \\
Membrane & 59 & 20 \\
\hline Nature of priming solution & 39 & 344 \\
All blood & & 155 \\
Full haemodilution & 288 & \\
Mixture of blood and electrolyte & & \\
solution & &
\end{tabular}

likely therefore that any inapparent, adverses effect derived from the use of an all-blood primeo in 1970 could be responsible for more than a veryo small proportion of the excessive incidence of neurological damage in that year.

Much greater uncertainty surrounds then accuracy of the data collection. The informations was derived retrospectively from the case notes and these had been completed by different staff $\overrightarrow{\vec{\omega}}$ It is quite possible that greater awareness of the problem of neurological damage in 1970 favoured more accurate and detailed assessment, and com ${ }_{i}$ ments on neurological status appeared more com? monly in the notes in 1970 . It is particularlys likely that minor degrees of dysfunction were not recorded in 1973, although the similarity in theo recorded incidence of confusion in patients with neurological damage $(27.5 \%$ in $1970 ; 25 \%$ ir 1973) does not support this possibility. The other lesions all represent major postoperative complica $=$ tions and it is likely they would be recorded. Furthermore, even if patients with confusion as the sole index of neurological dysfunction are excluded from the comparison, there is still a verys highly significant decrease in the incidence of neurological damage, from $13.9 \%$ in 1970 to $5.6 \%$ in $1973(\mathrm{P}<0.001)$.

This analysis suggests that none of the differ $\overrightarrow{\bar{A}}$ ences in the work, perfusion technique or data collection was sufficient to account for the re? duction in the incidence of neurological damage between 1970 and 1973. It must be concluded therefore that the introduction of prophylactio measures has been responsible for the improvece results. Unexpected neurological damage has not been eliminated entirely and there can be no roon for complacency until this ideal has beero achieved.

I am grateful to the surgeons of the Brompton Hospital for permission to study patients under theip. care, and to Miss C. M. Devine who kindly provided statistical assistance.

The study has been supported by a grant from the Medical Research Council, and the results form park of a thesis submitted for the degree of MD (Cantab).

\section{REFERENCES}

Branthwaite, M. A. (1972). Neurological damage re lated to open-heart surgery. Thorax, 27, 748. (1973). Detection of neurological damage during open-heart surgery. Thorax, 28, 464.

(1974). Cerebral blood flow and metabolisnæके during open-heart surgery. Thorax, 29, 633.

Egeblad, K., Osborn, J. J., Burns, W., Hill, J. D., and Gerbode, F. (1972). Blood filtration during car? 
diopulmonary bypass. Journal of Thoracic and Cardiovascular Surgery, 63, 384.

Hasbrouck, J. D. and Rigor, B. M. (1969). The oxygen tension of cerebrospinal fluid during cardiopulmonary bypass. Journal of Thoracic and Cardiovascular Surgery, 58, 754.

Hill, J. D., Osborn, J. J., Swank, R. L., Aguilar, M. J., de Lanerolle, P., and Gerbode, F. (1970). Experience using a new Dacron wool filter during extracorporeal circulation. Archives of Surgery, 101, 649.

Javid, H., Tufo, H. M., Najafi, H., Dye, W. S., Hunter, J. A., and Julian, O. C. (1969). Neurological abnormalities following open-heart surgery. Journal of Thoracic and Cardiovascular Surgery, 58, 502.

Osborn, J. J., Swank, R. L., Hill, J. D., Aguilar, M. J., and Gerbode, F. (1970). Clinical use of a Dacron wool filter during perfusion for open-heart surgery. Journal of Thoracic and Cardiovascular Surgery, 60, 575.
Patterson, R. H. Jr. and Kessler, J. (1969). A filter for micro-emboli in cardiopulmonary bypass (Abstract). Circulation, 40, Supplement 3, p. 160.

Sanderson, J. M., Wright, G., and Sims, F. W. (1972). Brain damage in dogs immediately following pulsatile and non-pulsatile blood flows in extracorporeal circulation. Thorax, 27, 275.

Stone, H. H., Nusbaum, M., Donnelly, C. C., Blakemore, W. S., and Zinsser, H. F. (1967). Lactate and pyruvate differences across the brain of man during cardiopulmonary bypass (Abstract). Circulation, 36, Supplement 2, p. 244.

Tufo, H. M., Ostfeld, A. M., and Shekelle, R. (1970). Central nervous dysfunction following open-heart surgery. Journal of the American Medical Association, 212, 1333.

Requests for reprints to: Dr. M. A. Branthwaite, Brompton Hospital, Fulham Road, London SW3 6HP. 